\title{
Liquidity Externalities and Information Spillover between the Equity and Corporate Bond Markets: An Empirical Study
}

\author{
Hao Yin \\ Advanced Research Center, State Street Global Advisors \\ One Lincoln Street, Boston, MA 02111, USA \\ Tel: 1-812-391-2594 E-mail: hao_yin@ssga.com
}

Received: April 16, 2011

Accepted: April 25, 2011

doi:10.5539/ijef.v3n5p65

\begin{abstract}
Information spillover and liquidity externality across securities is of practical importance to both practitioners and policy makers. We empirically examine how information spillover facilitates liquidity externalities between the equity and corporate bond markets. An event study was conducted by comparing the change of liquidity of stocks whose corporate bonds are TRACE-eligible with that of non-TRACE-eligible control stocks around the initiation of the TRACE system. It is found that the TRACE initiation significantly reduced the illiquidity of corresponding common stocks, which provide empirical evidence supporting the hypothesis of cross-market liquidity externalities.
\end{abstract}

Keywords: Liquidity externalities, Information spillover, Transparency, TRACE

JEL Classification Number: D82, G14, G19

\section{Introduction}

Amihud et al. (1997) define "liquidity externalities" to be "when the prices of two securities are correlated, an improvement in the liquidity of one should improve the liquidity of the other". It remains one of the most important issues in market microstructure literature (Madhavan (2000)) and has spurred a great deal of study in the last decade. Theoretically speaking, there are mainly two mechanisms underlying the liquidity externalities, the network effect and the information spillover (see Amihud and Mendelson (1991)). Network effect arises when traders can come together both spatially and temporally, resulting in lower search costs and transaction costs. The lower transaction costs in turn attract more traders and build up a positive feedback, or liquidity externality. Information spillover is mostly due to the adverse selection problem. Intuitively, because price information is a public good, improved value discovery for one security facilitates value discovery for the other (correlated) security (Amihud et al. (1997)). The present paper examines the effect of information spillover on liquidity externalities between the equity and corporate bond markets, and provides empirical evidences by studying the initiation of the TRACE (Trade Reporting and Compliance Engine) system in the corporate bond market.

The main contribution to the literature is the empirical documenting of the liquidity externalities between the equity and the corporate bond markets. There have been numerous empirical studies on the network effect of liquidity externalities, under either a single-security multi-market (e.g. Barclay and Hendershott (2004) and Hendershott and Jones (2005)) or multi-security (e.g. Choi et al. (2007)) framework. But empirically studying information spillover mechanisms is more subtle, and is normally conducted by examining the shift of market transparency of one security and the associated liquidity change of the related security in the same market. For example, Amihud et al. (1997) investigate the liquidity change of "twin stocks", i.e., two different classes of stock of the same company of which the "primary stock" was transferred to the new trading method on the Tel Aviv Stock Exchange while the "secondary stock" was not. They find liquidity improvements in both stocks, although in different magnitudes. Instead of the equity market, Bessembinder et al. (2006) examine the trading costs change in the U.S. corporate bond market due to the higher transparency brought by the TRACE system and find that the trading costs fell for both TRACE-eligible and non-TRACE-eligible bonds. Different from the above work on stock-stock or bond-bond externalities, our paper investigates the liquidity externalities between the equity and corporate bond markets. Because of the natural differences in investor characteristics and market environment, the network effect across these two markets should be arguably much weaker than in either of them, enabling us to better isolate the effect of information spillover.

The main hypothesis to test is that the post-trade transparency in the corporate bond market improves the liquidity in the equity market. The initiation of the TRACE system provides us a natural experiment to empirically test this hypothesis. Using the TAQ (Trades and Quotes) data from 2002, we compare the differences in effective spread, 
realized spread, adverse selection and quoted spread between "TRACE-eligible" stocks and their matched control stocks around the TRACE launch. The matching is based on the factors known to have market microstructure influences, including price, market capitalization, trade volume and volatility. We find that illiquidity of the TRACE-eligible stocks (defined below) reduced significantly after the TRACE launch, no matter whether it is measured by effective spread, realized spread or adverse selection component. And this is true even after controlling for the price level, trade size, trade frequency and volatility. Therefore the empirical results confirm our theoretical prediction that information spillover from the corporate bond market does improve the liquidity in the corresponding equity market.

\section{Related literature}

Although the last decade has witnessed rapid development of transparency studies in the finance literature, to the best of our knowledge, this paper is the first to examine the relationship of transparency and liquidity between the equity and corporate bond markets. Based on the model by Kyle (1985), Chowdhry and Nanda (1991) propose a single-asset multi-market model, and conclude that transparency can bring in higher liquidity by "cracking down" on informed trading. Consistent with their results, Pagano and Roell (1996) also show that greater transparency reduces transaction costs incurred by uninformed traders. Introducing a risk-averse dealer, Naik et al. (1999) develop a model where better transparency can cut the inventory cost of the dealer by improving inventory risk sharing. Although most of the theoretical models predict a positive relationship between transparency and liquidity, Madhavan (1995) provides a counter-point. By introducing large liquidity traders into the model, he argues that nondisclosure may benefit certain types of market participants and thus validate market fragmentation.

The existing empirical studies on relationship between market transparency and liquidity are also limited on the own-market effect and the conclusions are mixed. For example, while Flood et al. (1999) and Boehmer et al. (2005) document greater liquidity associated with increased pre-trade transparency, Madhavan et al. (2005) find the opposite. Using laboratory experiments, Bloomfield and O'Hara (1999) show that the market characteristics are little affected by the quote disclosure (Pre-trade transparency) but are much affected by the trade disclosure (Post-trade transparency), which is exactly what the TRACE system brought to the corporate bond market. Unsurprisingly, the introduction of the TRACE system spurs more empirical researche on the U.S. corporate bond market. One of the recent studies is Bessembinder et al. (2006), who investigate the trading costs change due to the higher transparency brought by the TRACE system and find that the trading costs fell about a half for TRACE-eligible bonds. A contemporary work is by Edwards et al. (2006), who examine determinants of cross-sectional variation in trading costs for corporate bonds using the TRACE data. They report lower costs for bonds with more transparent trade prices, similar to the finding of reduced spreads on newly transparent BBB corporate bonds documented by Goldstein et al (2007). However, no matter what conclusions the above papers reach, they look into only the "own-market" effect of transparency, while our paper studies the cross-market effect of transparency between the equity and corporate bond markets.

Empirical studies on cross-market effect of liquidity are relatively sparse as well, with the majority of the works focusing on the relationship between the equity and U.S. Treasury bond markets. One pioneering study is Chordia et al. (2005), which examines the joint dynamics and finds a significantly positive correlation between the stock and Treasury bond market liquidities. Using sample over a longer time span, Goyenko and Ukhov (2008) document Granger causality between these two asset classes in both directions. There are two main aspects in which our paper differs from the above research. One is that rather than the U.S Treasury bond market, we analyze the interaction of the corporate bond market with the equity market. This makes huge difference since the Treasury bond market is mostly driven by macroeconomic level innovations (such as monetary policy), but the corporate bond market is largely driven by microeconomic level innovations (such as capital structure of the firm) and thus share more information asymmetry with the equity market. In addition, unlike the preceding literatures focusing on the cross-market liquidity-to-liquidity effect, our paper mainly looks into the role played by the transparency in the cross-market liquidity effect.

\section{Data}

Traditionally, the U.S. equity markets are quite transparent, where both pre-trade and post-trade information is disseminated to public continuously. In contrast, the corporate bond market is much more opaque, where neither Pre-trade nor Post-trade information is available in real time. The main reason is that unlike equity markets, which are mostly centered in organized exchanges, corporate bonds are traded over-the-counter (OTC). The transparency of the corporate bond market did not begin to improve significantly until the introduction of the TRACE system. At 8am EDT on July 1, 2002, NASD began to disseminate to average investors the Post-trade information of about 500 eligible corporate bonds, including the date and time of transaction, price, yield, and some quantity information. 
This dramatically increased the Post-trade transparency of these 500 corporate bonds, which according to our theoretical hypothesis should also bring positive liquidity externalities to the equity markets of the same issuers. In this section, we empirically test this hypothesis by examining the liquidity of the "TRACE-eligible" stocks before and after the launch of the TRACE system.

Our sample period covers from January 2, 2002 to December 31, 2002, six months before and after the launch date of TRACE. The six-month period is believed long enough to allow market participants time to familiarize themselves with the new system. According to the NASD TRACE Fact Book (2006), "during Phase I, effective on July 1, 2002, public transaction information was disseminated immediately upon receipt for the larger and generally higher-credit quality issues". Those include (1) Investment Grade debt securities having an initial issue of $\$ 1$ billion or greater; and (2) 50 Non-Investment Grade (High-Yield) securities disseminated under FIPS2 that were transferred to TRACE. Under these criteria, by the end of 2002 there were approximately 520 "TRACE-eligible" corporate bonds reported through the system.

After downloading the transaction data of these "TRACE-eligible" bonds in 2002 from the Center for Research in Security Prices (CRSP) database, we exclude all the bonds with less than 100 trades in the 6 months after July 01 , 2002. This is to ensure that the corporate bond market for each security is liquid enough to be informative for the market participants on both corporate bond market and equity market, to provide sufficient "information effect". Then we match the issuer's ticker symbol with the equity ticker symbol in the CRSP dataset, ending up with 173 stocks. Next we delete those stocks not traded in 2002. Using a similar filter as in Bacidore and Sofianos (2002), we also eliminate all the stocks with (1) daily close price below $\$ 1$ or above $\$ 500$ in any day, or (2) overnight decline of $40 \%$ or more to control for stock splits. The final sample has 130 stocks on 252 trading days.

Since our study examines a single event on one date, it is critical to construct a matched "non-TRACE-eligible" sample of stocks to ensure that the observed liquidity changes are actually caused by the TRACE initiation instead of other market-wide structural changes. We take matching criteria which are somewhat standard in the market microstructure literature (see Huang and Stoll (1996), Bacidore and Sofianos (2002) and Battalio et al (2007)), including price, market capitalization, trade volume and price volatility. To make sure the matching is closest around the TRACE initiation date, we use the two months right before that date, May 1, 2002 to June 30, 2002, as the calculation window. The price is the average daily closing price over this window. The market capitalization is calculated as the average daily closing price multiplied by the number of shares outstanding in these two months. The trade volume is the average daily trading volume in number of shares during this period. The price volatility is computed as the natural logarithm of the ratio of the highest ask price and lowest bid price for every day, and then averaged over all trading days over the calculating window. After obtaining the values of these four variables for each of the 130 TRACE-eligible stocks, we identify a matching Non-TRACE-eligible stock that minimizes the equation:

$$
\sum\left(\left(c_{i}-c_{i}^{\text {matching }}\right) /\left(\left(c_{i}+c_{i}^{\text {matching }}\right) / 2\right)\right)^{2},
$$

where $c_{i},(i=1,2,3,4)$ is price, market capitalization, trade volume and price volatility, respectively, by searching all the "non-TRACE-eligible" stocks available in the TAQ data set of CRSP for the "one-to-one nearest neighbor" with replacement.

After identifying the 130 pairs of stocks, we obtain the TAQ data for all of them from January 2, 2002 to December 31, 2002 from Wharton Research Data Services (WRDS). To filter the trade data, we first restrict trades to between 9:45 AM and 4:00 PM to eliminate the effect of market opening call auction. Then we delete trades with a Condition Code of ' $Z$ ' or ' $G$ ' or a Correction Code exceeding one to exclude the mis-reported trades. To filter the quote data, we omit quotes if either the ask or bid price is non-positive, or they are non-firm (TAQ quote condition codes 4, 7, 9, $11,13,14,15,19,20,27$ and 28). Furthermore, since many stocks are listed on multiple market venues, we compare the contemporaneous quotes at any given time to get the National Best Bid and Offer (NBBO) quotes.

Our hypothesis is that transparency of the corporate bond market tightens the spread in the corresponding equity market. In the empirical microstructure literature, there are several measures of spread to address the level of market liquidity, namely, the time-weighted average quoted spread, the share-weighted average effective spread, and the share-weighted average realized spread. The relative quoted spread, measuring the "displayed" cost of immediacy, is calculated as the difference between the prevailing national best ask $\left(A s k_{t}\right)$ and national best bid $\left(\operatorname{Bid}_{t}\right)$ standardized by the midquote $\left(M_{t}\right)$ as,

$$
Q S_{t}=\left(A s k_{t}-B_{i d}\right) / M_{t} .
$$

The relative effective spread is defined as twice the absolute difference between the trade price and the midpoint of the prevailing NBBO quotes at the time of the trade, standardized by the midquote as, 


$$
E S_{t}=2 \times\left|P_{t}-M_{t}\right| / M_{t},
$$

where $P_{t}$ is the trade price at time $t$. Because of the probability of "price improvement", the effective spread is arguably more representative of the "actual" cost of immediacy.

To address the issue of how much information asymmetry contributes to the spread, we also compute the relative realized spread defined as

$$
R S_{t}=\text { Side } \times 2 \times\left(P_{t}-M_{t+T}\right) / M_{t},
$$

where Side is 1 for buyer-initiated trade and -1 for seller-initiated trade, and $M_{t+T}$ is the midquote price $T$ minutes after the trade. Intuitively, the realized spread provides an estimate of the gross trading revenue earned by the liquidity providers. In order to infer the side of each trade (buy or sell), we use the Lee and Ready (1991) algorithm with the adjustment proposed by Bessembinder (2003) to accommodate the more active modern trading environment. As in Battalio et al (2007), we set $T$ equal to 5 minutes. In addition, we calculate the adverse selection component of the spread as the difference between the effective spread (i.e., what investors pay) and the realized spread (i.e., what liquidity providers earn) as

$$
A D S_{t}=E S_{t}-R S_{t} \text {. }
$$

If the higher transparency in the corporate bond market helps to lessen the information asymmetry problem in the equity market, we would expect to observe smaller adverse selection component after the TRACE launch.

\section{Empirical analysis}

Table 1 presents the descriptive statistics for the "TRACE-eligible" stocks and their matched control stocks. Both sample stocks and control stocks have a median price around $\$ 34$, a median market capitalization of $\$ 14$ billion, and a median volatility about 0.03 . The median trade volumes are slightly different from each other, but the mean, minimum and maximum are reasonably close. Overall the statistics of the matching variables are similar between these two sets of stocks, suggestion that we are quite successful in identifying matching stocks for the "TRACE-eligible" stocks.

To examine the impact of the TRACE launch on the liquidity of the equity market, we begin with a univariate analysis on the relative effective spread which arguably reflects the most "actual" measure of the transaction costs. Table 2 provides the daily "differences in differences" of the relative effective spreads between the "TRACE-eligible" stocks and their matched stocks from June 1, 2002 to August 31, 2002, one month before and two months after the TRACE initiation. We first calculate the daily differences in the effective spread between each "TRACE-eligible" stock and its matched stock. Then we compute the average of these daily differences over the base period from March 1, 2002 to May 31, 2002 and subtract it from the difference for each pair on each event day. The cross-sectional mean and median of these "differences in differences" are reported in the table. The alternative hypothesis of the one-tail t-test (Wilcoxon test) is that the mean (median) difference in relative effective spread on each event day is smaller than that in the base period, which is from March 1, 2002 to May 31, 2002. The t-test is conducted using the standardized cross-sectional statistics proposed by Boehmer et al (1991), which is more robust than the traditional t-test. The difference in median is tested using the Wilcoxon Signed Rank approach.

As shown in Table 2, the median relative effective spreads of "TRACE-eligible" stocks are significantly smaller than those of their matched "non-TRACE-eligible" stocks in 11 out of the 44 trading days right after the TRACE initiation, but are significantly smaller in only 2 out of the 20 trading days before the TRACE initiation. For average relative effective spreads, 9 trading days are significant after the TRACE initiation while 3 trading days are significant before the TRACE initiation. This suggests that the launch of TRACE tends to reduce the effective spread of those "TRACE-eligible" stocks, consistent with what the hypothesis predicts. Another observation is that, although the effective spreads are generally smaller after the TRACE initiation, the reductions are relatively scattered instead of clustered over time.

Although the Wilcoxon Signed Rank test shows the decrease of spread of "TRACE-eligible" stocks due to the TRACE launch, the t-test produces less conclusive results. In addition, we need to determine whether the results are actually driven by other market microstructure factors. We thus consider a multivariate setting as given by the following time-series cross-section regression

$$
\Delta E S_{i t}=\alpha+\beta_{1} \times \Delta \text { PInv }_{i t}+\beta_{2} \times \Delta \text { TradeSize }_{i t}+\beta_{3} \times \Delta \text { NumTrade }_{i t}+\beta_{4} \times \Delta \text { Volat }_{i t}+\beta_{5} \times T_{R A C E}+u_{i}+\varepsilon_{i t},
$$

where all the $\Delta \mathrm{s}$ are the differences in the corresponding variables between the "TRACE-eligible" stock and its matched control stock for pair $i$ and day $t, E S$ is the relative effective spread, PInv is the inverse of the average midquote price on each day, TradeSize is the daily average trade size in number of shares, NumTrade is the number of trades on each day, Volat is the price volatility defined as the range of midquote on each day, 
standardized by the average midquote, and TRACE is a dummy variable which takes value of one if the date is before July 1, 2002 and zero otherwise. $u_{i}$ is the fixed effect to handle the stock-level heterogeneities (such as market value), and $\varepsilon_{i t}$ is the error term. The rationale of choosing these control variables is following Stoll (2000), who argues that the most important determinants of transaction cost include trading volume, security price, price volatility, number of trade, and market value. The hypothesis to test is whether the initiation of TRACE has impact on the liquidity of the "TRACE-eligible" stocks after controlling for these factors.

The multivariate regression results are summarized in Table 3, where the standard errors are calculated using the Huber-White sandwich estimator to control for heteroskedasticity in the error terms. The first column in Panel A presents the result of regression using the full sample. Holding other things constant, the "TRACE-eligible" stocks have significantly wider relative effective spreads if they have lower per share price, if their average trade size is larger, if they trade less frequently, or if their price is more volatile relative to their matched control stocks. These results are in line with the observations documented by Battalio et al (2007) and other market microstructure papers. However, what interests us most is the coefficient of the dummy variable TRACE, the value of which is significantly negative at $1 \%$ level, indicating that the effective spreads of the "TRACE-eligible" stocks are significantly smaller after the TRACE system was launched for all stocks.

Although the full-sample regression provides evidence supporting our theoretical prediction, we need to check whether this result is robust along different dimensions of stock characteristics, or is just driven by certain subgroups. We start with the ratings of the corporate bonds issued by the same firm. First we obtain the most recent Standard \& Poor's ratings before July 1, 2002 for all the "TRACE-eligible" corporate bonds, and calculate the average bond ratings for each firm where AAA is $1, \mathrm{AA}+$ is 2, etc, as in Eom et al (2004). Then we sort all the stocks by the average bond rating and partition them into three equal-size portfolios, from the highest (AAA) to the lowest ratings. The regression results for these three portfolios are listed in column 2, 3 and 4 in Panel A of Table 3 . The coefficients of the dummy variable TRACE remain significantly negative across all the three groups, while the stocks with the highest and lowest corporate bond ratings tend to have stronger effect than those with middle ratings.

Another possibility is that the significance of our result could be solely driven by a few stocks with extremely high probability of informed trading. To check this, we subset the stocks into three groups using the Probability of Informed Trading (PIN) as the criterion and the show results in Panel B of Table 3. The PINs of these stocks are downloaded from the website of Steven Brown, and we use the second quarter of 2002 as the estimation period. As seen in the table, the reduction of effective spread after the launch of the TRACE system is uniformly significant and negative in all the three PIN subsets. Note that, surprisingly, stocks with lower probability of informed trading tend to have stronger "cross-market" effect. This is consistent with the pattern we observe in Panel A, where higher rated stocks have larger reduction in the effective spreads. Actually, the Pearson Correlation Coefficient between the average bond rating (AAA is $1, \mathrm{AA}+$ is 2 , etc.) and the PIN is $23.4 \%$ and significant at $5 \%$, suggesting higher rated stocks have lower probability of informed trading.

As the last breakdown of the full sample by stock characteristics, Panel C of Table 3 presents the results for the three portfolios partitioned according to the average trading frequency of the corporate bonds of each stock, measured by total number of bond trades from July 1, 2002 to December 31, 2002. The coefficients of the dummy variable TRACE are all significantly negative and similar across the subsets. Thus we can conclude that reduction in effective spreads due to the TRACE launch is quite robust across the spectra of bond rating, probability of informed trading and bond trading frequency. Coupling with the findings by Bessembinder et al. (2006) and Edwards et al. (2006), we confirm our prediction that higher transparency in the corporate bond market leads to more liquidity in both the corporate bond market and the equity market.

The effective spread can be further decomposed into two components, the realized spread and the adverse selection component. It is interesting to investigate how these two components of the "TRACE-eligible" stocks are impacted by the TRACE launch, since they represent different sources of the transaction costs paid by the liquidity demanders. If the information spillover contributes to liquidity externalities, we would expect significant reduction in the adverse selection component. We run the same fixed-effect regressions on these two variables as on the effective spread, and the outcomes are presented in first two columns of Table 4.

As shown in the table, with the exception of price level and to some extent trading frequency, realized spread is quite immune to other market microstructure variables, implying the constancy of gains earned by liquidity providers. In contrast, we observe that the adverse selection problem is worsened not only by higher price volatility, but also by less frequent trades. Of particular interest, we find out that both the adverse selection component is significantly smaller for the "TRACE-eligible" stocks after the TRACE system was initiated. This suggests that a more transparent corporate bond market lessens the information asymmetry problem in the equity market as well, 
providing evidence for the information spillover. Note that the realized spread is also smaller, indicating reduced profits for liquidity providers as well.

For the purpose of comparison, we list the regression output of relative quoted spread in the last column of Table 4 . The results are generally similar to those of adverse selection component, except that no significant effect of the TRACE launch is found. The reason might be that the quoted spread is just "displayed" cost of immediacy and relevant only for small trades, while the effective spread is the "actual" cost of immediacy and relevant for both small and large trades. Thus we can not expect as much of impact on the quoted spread as shown for the effective spread.

To summarize, in this section we compare the liquidity of the "TRACE-eligible" stocks before and after the TRACE launch and consistently find that the effective spread and its two components, realized spread and adverse selection, are all significantly smaller relative to their matched control stocks after the TRACE launch, confirming the existence of liquidity externalities between the equity and corporate bond markets.

\section{Conclusion}

Liquidity externality is a topic of considerable importance and to understand the mechanisms underlying it has been of particular interest in the market microstructure literature. Most existing studies, however, focus on the network effects of a single security on multiple markets. In this paper we analyze the liquidity externalities between the equity and corporate bond markets, testing whether greater transparency in the corporate bond market can reduce the transaction costs in the equity market as well.

Specifically, we test the hypothesis by comparing the change in liquidity of those "TRACE-eligible" stocks versus that of their matched "Non-TRACE-eligible" stocks. We find that spreads are significantly smaller for "TRACE-eligible" stocks after the launch of the TRACE system, relative to their matched stocks. In addition to the prior research by Amihud et al. (1997) and Bessembinder et al. (2006) who study either stock-stock or bond-bond externalities, our results complement the empirical literature by documenting the existence of cross-market liquidity externalities caused by information spillovers.

\section{Reference}

Admati, A. (1985). A noisy rational expectations equilibrium for multi-asset securities markets. Econometrica 53, 629-658. doi:10.2307/1911659, http://dx.doi.org/10.2307/1911659

Amihud, Y. \& Mendelson, H. (1991). How (not) to integrate the European capital markets. In: Giovannini, A., Mayer, C. (Eds.). European Financial Integration. Cambridge University Press, Cambridge, MA, 73-99. doi:10.1017/CBO9780511752070.008, http://dx.doi.org/10.1017/CBO9780511752070.008

Amihud, Y., Mendelson, H. \& Lauterbach, B. (1997). Market microstructure and securities values: Evidence from the Tel Aviv Stock Exchange. Journal of Financial Economics 45, 365-390. doi:10.1016/S0304-405X(97)00021-4, http://dx.doi.org/10.1016/S0304-405X(97)00021-4

Bacidore, J. \& Sofianos, G. (2002). Liquidity provision and specialist trading in NYSE-listed non-U.S. stocks. Journal of Financial Economics 63, 133-158. doi:10.1016/S0304-405X(01)00092-7, http://dx.doi.org/10.1016/S0304-405X(01)00092-7

Barclay, M. \& Hendershott, T. (2004). Liquidity externalities and adverse selection: evidence from trading after hours. Journal of Finance 59, 681-710. doi:10.1111/j.1540-6261.2004.00646.x, http://dx.doi.org/10.1111/j.1540-6261.2004.00646.x

Battalio, R., Ellul, A. \& Jennings, R. (2007). Reputation effects in trading on the New York Stock Exchange. Journal of Finance 62, 1243-1271. doi:10.1111/j.1540-6261.2007.01235.x, http://dx.doi.org/10.1111/j.1540-6261.2007.01235.x

Bernhardt, D. \& Taub, B. (2008). Cross-asset speculation in stock markets. Journal of Finance 63, 2385-2427. doi:10.1111/j.1540-6261.2008.01400.x, http://dx.doi.org/10.1111/j.1540-6261.2008.01400.x

Bessembinder, H. (2003). Issues in assessing trade execution costs. Journal of Financial Markets 6, 233-257. doi:10.1016/S1386-4181(02)00064-2, http://dx.doi.org/10.1016/S1386-4181(02)00064-2

Bessembinder, H., Maxwell, W. \& Venkataraman, K. (2006). Market transparency, liquidity externalities, and institutional trading costs in corporate bonds. Journal of Financial Economics 82, 251-288. doi:10.1016/j.jfineco.2005.10.002, http://dx.doi.org/10.1016/j.jfineco.2005.10.002

Bloomfield, R. \& O'Hara, M. (1999). Market transparency: who wins and who loses? Review of Financial Studies 12, 5-35. doi:10.1093/rfs/12.1.5, http://dx.doi.org/10.1093/rfs/12.1.5 
Boehmer, E., Musumeci, J. \& Poulsen, A. (1991). Event-study methodology under conditions of event-induced variance. Journal of Financial Economics 30, 253-272. doi:10.1016/0304-405X(91)90032-F, http://dx.doi.org/10.1016/0304-405X(91)90032-F

Boehmer, E., Saar, G. \& Yu, L. (2005). Lifting the veil: an analysis of pre-trade transparency at the NYSE. Journal of Finance 60, 783-815. doi:10.1111/j.1540-6261.2005.00746.x, http://dx.doi.org/10.1111/j.1540-6261.2005.00746.x

Choi, D., Getmansky, M. \& Tookes, H. (2009). Convertible bond arbitrage, liquidity externalities and stock prices. Journal of Financial Economics 91,227-251.

Chordia, T., Sarkar, A. \& Subrahmanyam, A. (2005). An empirical analysis of stock and bond market liquidity. Review of Financial Studies 18, 85-129 doi:10.1093/rfs/hhi010, http://dx.doi.org/10.1093/rfs/hhi010

Chowdhry, B. \& Nanda, V. (1991). Multimarket trading and market liquidity. Review of Financial Studies 4, 483-511. doi:10.1093/rfs/4.3.483, http://dx.doi.org/10.1093/rfs/4.3.483

Davies, R. \& Kim, S.S. (2007). Using matched samples to test for differences in trade execution costs. Journal of Financial Markets 12, 173-202

Easley, D., Kiefer, N. \& O'Hara, M. (1997). One day in the life of a very common stock. Review of Financial Studies 10, 805-836. doi:10.1093/rfs/10.3.805, http://dx.doi.org/10.1093/rfs/10.3.805

Edwards, A., Harris, L. \& Piwowar, M. (2007). Corporate bond market transaction costs and transparency. Journal of Finance 62, 1421-1451. doi:10.1111/j.1540-6261.2007.01240.x, http://dx.doi.org/10.1111/j.1540-6261.2007.01240.x

Eom, Y.H., Helwege, J. \& Huang, J.Z. (2004). Structural models of corporate bond pricing: An empirical analysis. Review of Financial Studies 17, 499-544. doi:10.1093/rfs/hhg053, http://dx.doi.org/10.1093/rfs/hhg053

Fleming, J., Kirby, C. \& Ostdiek, B. (1998). Information and volatility linkages in the stock, bond, and money markets. Journal of Financial Economics 49, 111-137. doi:10.1016/S0304-405X(98)00019-1, http://dx.doi.org/10.1016/S0304-405X(98)00019-1

Flood, M., Huisman, R., Koedijk, K. \& Mahieu, R. (1999). Quote disclosure and price discovery in multiple-dealer financial markets. Review of Financial Studies 12, 37-59. doi:10.1093/rfs/12.1.37, http://dx.doi.org/10.1093/rfs/12.1.37

Garbade, K., Pomrenze, J. \& Silber, W. (1979). On the information content of prices. American Economic Review 69, 50-59.

Gemmill, G. (1996). Transparency and liquidity: A study of block trades on the London Stock Exchange under different publication rules. Journal of Finance 51, 1765-1790. doi:10.2307/2329537, http://dx.doi.org/10.2307/2329537

Goldstein, M., Hotchkiss, E. \& Sirri, E. (2007). Transparency and liquidity: A controlled experiment on corporate bonds. Review of Financial Studies 20, 235-273. doi:10.1093/rfs/hhl020, http://dx.doi.org/10.1093/rfs/hhl020

Goyenko, R. \& Ukhov, A. (2009). Stock and bond market liquidity: A long-run empirical analysis. Journal of Financial and Quantitative Analysis 44, 189-212. doi:10.1017/S0022109009090097, http://dx.doi.org/10.1017/S0022109009090097

Hendershott, T. \& Jones, C. (2005). Island goes dark: transparency, fragmentation, and regulation. Review of Financial Studies 18, 743-793. doi:10.1093/rfs/hhi013,http://dx.doi.org/10.1093/rfs/hhi013

Henker, T. \& Wang, J.X. (2006). On the importance of timing specifications in market microstructure research. Journal of Financial Markets 9, 162-179. doi:10.1016/j.finmar.2006.01.001, http://dx.doi.org/10.1016/j.finmar.2006.01.001

Huang, R. \& Stoll, H. (1996). Dealer versus auction markets: A paired comparison of execution costs on Nasdaq and the NYSE. Journal of Financial Economics 41, 313-357. doi:10.1016/0304-405X(95)00867-E,http://dx.doi.org/10.1016/0304-405X(95)00867-E

Keim, D. \& Stambaugh, R. (1986). Predicting returns in the stock and bond markets. Journal of Financial Economics 17, 357-300. doi:10.1016/0304-405X(86)90070-X, http://dx.doi.org/10.1016/0304-405X(86)90070-X

Kwan, S. (1996). Firm-specific information and the correlation between individual stocks and bonds. Journal of Financial Economics $\quad 40, \quad 63-80 . \quad$ doi:10.1016/0304-405X(95)00836-4, http://dx.doi.org/10.1016/0304-405X(95)00836-4

Kyle, A. (1985). Continuous auctions and insider trading. Econometrica 53, 1315-1335. doi:10.2307/1913210, http://dx.doi.org/10.2307/1913210 
Lee, C. and Ready, M. (1991). Inferring trade direction from intraday data. Journal of Finance 46, 733-746. doi:10.2307/2328845, http://dx.doi.org/10.2307/2328845

Madhavan, A. (1995). Consolidation, fragmentation, and the disclosure of trading information. Review of Financial Studies 8, 579-603. doi:10.1093/rfs/8.3.579, http://dx.doi.org/10.1093/rfs/8.3.579

Madhavan, A. (2000). Market microstructure. Journal of Financial Markets 3, 205-258. doi:10.1016/S1386-4181(00)00007-0, http://dx.doi.org/10.1016/S1386-4181(00)00007-0

Madhavan, A., Porter, D. \& Weaver, D. (2005). Should securities markets be transparent? Journal of Financial Markets 8, 266-288. doi:10.1016/j.finmar.2005.05.001, http://dx.doi.org/10.1016/j.finmar.2005.05.001

Naik, N., Nueberger, A. \& Viswanathan, S. (1999). Disclosure regulation in markets with negotiated trades. Review of Financial Studies 12, 873-900. doi:10.1093/rfs/12.4.873, http://dx.doi.org/10.1093/rfs/12.4.873

NASD. (2006). TRACE fact book 1-4. [Online] Available: www.nasd.com.

Pagano, M. \& Roell, A. (1996). Transparency and liquidity: A comparison of auction and dealer markets with informed trading. Journal of Finance 51, 579-611. doi:10.2307/2329372, http://dx.doi.org/10.2307/2329372

Odders-White, E. \& Ready, M. (2008). The probability and magnitude of information events. Journal of Financial Economics 87, 227-248.

Stoll, H. (2000). Presidential address: Friction. Journal of Finance 55, 1479-1514. doi:10.1111/0022-1082.00259, http://dx.doi.org/10.1111/0022-1082.00259

Acknowledgement: This paper is based on the author's dissertation completed at the Indiana University. The views expressed are the views of Hao Yin, only through the period ended April $25^{\text {th }}, 2011$, and do not necessarily reflect the views of State Street Corporation. The information provided does not constitute investment advice and should not be considered a solicitation to buy or an offer to sell a security. All material has been obtained from sources believed to be reliable, but its accuracy is not guaranteed. The author thanks Craig Holden, Mark Hooker and Konstantin Tyurin for stimulating discussions and helpful comments

Table 1. Summary Statistics for "TRACE-eligible" and Matched Control Stocks

\begin{tabular}{|c|c|c|c|}
\hline \multicolumn{2}{|c|}{ Sample size } & Sample & Control \\
\hline & & 130 & 130 \\
\hline \multirow{5}{*}{$\begin{array}{l}\text { Price } \\
\text { (in dollars) }\end{array}$} & Mean & 35.21 & 35.90 \\
\hline & Median & 33.94 & 34.88 \\
\hline & Min & 2.99 & 2.74 \\
\hline & $\operatorname{Max}$ & 91.42 & 98.67 \\
\hline & Std. Dev & 20.56 & 20.36 \\
\hline \multirow{5}{*}{$\begin{array}{r}\text { Market capitalization } \\
\text { (in thousand dollars) }\end{array}$} & Mean & $31,544,430$ & $25,805,226$ \\
\hline & Median & $13,973,556$ & $14,026,760$ \\
\hline & Min & 28,474 & 36,708 \\
\hline & Max & $306,404,251$ & $287,118,781$ \\
\hline & Std. Dev & $49,342,931$ & $36,141,392$ \\
\hline \multirow{5}{*}{$\begin{array}{l}\text { Trade volume } \\
\text { (in shares) }\end{array}$} & Mean & $3,929,405$ & $4,167,809$ \\
\hline & Median & $2,307,201$ & $1,790,951$ \\
\hline & Min & 19,698 & 18,844 \\
\hline & Max & $41,930,581$ & $39,696,694$ \\
\hline & Std. Dev & $5,663,394$ & $6,478,836$ \\
\hline \multirow[t]{5}{*}{ Volatility } & Mean & 0.034 & 0.035 \\
\hline & Median & 0.029 & 0.030 \\
\hline & Min & 0.012 & 0.011 \\
\hline & $\operatorname{Max}$ & 0.112 & 0.104 \\
\hline & Std. Dev & 0.018 & 0.017 \\
\hline
\end{tabular}

The sample stocks were "TRACE-eligible" as of July 1, 2002. Each sample stock is matched with a "non-TRACE-eligible" stock on the basis of price, market capitalization, trade volume and volatility, which were calculated using the NYSE Trade and Quote (TAQ) data. Price is the daily closing price. Market capitalization is the daily closing price multiplied by number of shares outstanding on that day. Trade volume is daily trading volume. Volatility is the log of ratio of intraday high ask to intraday low bid prices. All variables are daily averaged from May 1, 2002 to June 30, 2002. 
Table 2. Differences in Differences between the Share-Weighted Relative Effective Spreads of "TRACE-eligible" Stocks and Matched Control Stocks

\begin{tabular}{|c|c|c|c|c|c|}
\hline Date & Mean & Median & Date & Mean & Median \\
\hline 3-Jun-2002 & 13.13 & -0.18 & 18-Jul-2002 & 4.76 & -1.66 \\
\hline 4-Jun-2002 & -1.45 & -0.27 & 19-Jul-2002 & $-71.48^{*}$ & -1.28 \\
\hline 5-Jun-2002 & 11.30 & 0.62 & 22-Jul-2002 & -20.90 & 0.56 \\
\hline 6-Jun-2002 & 15.12 & -0.77 & 23-Jul-2002 & -2.00 & -0.57 \\
\hline 7-Jun-2002 & 5.07 & 0.96 & 24-Jul-2002 & 2.78 & 0.64 \\
\hline 10-Jun-2002 & -5.68 & -0.16 & 25-Jul-2002 & -27.00 & -0.56 \\
\hline 11-Jun-2002 & 2.47 & -0.69 & 26-Jul-2002 & -2.39 & -1.15 \\
\hline 12-Jun-2002 & -29.67 & 0.43 & 29-Jul-2002 & -24.96 & $-2.85 * *$ \\
\hline 13-Jun-2002 & $-22.60 * *$ & $-0.85 *$ & 30-Jul-2002 & -17.12 & -0.06 \\
\hline 14-Jun-2002 & 6.96 & 0.62 & 31-Jul-2002 & -21.16 & -0.51 \\
\hline 17-Jun-2002 & -1.03 & -0.91 & 1-Aug-2002 & -96.34 & 0.37 \\
\hline 18-Jun-2002 & -1.11 & -0.41 & 2-Aug-2002 & -122.66 & -0.90 \\
\hline 19-Jun-2002 & $-2.06^{*}$ & -1.19 & 5-Aug-2002 & 4.22 & 0.74 \\
\hline 20-Jun-2002 & -22.09 & -1.47 & 6-Aug-2002 & $-21.34^{*}$ & $-2.69 * *$ \\
\hline 21-Jun-2002 & $-18.51^{*}$ & $-1.28 * *$ & 7-Aug-2002 & -24.15 & -1.11 \\
\hline 24-Jun-2002 & -27.28 & -0.65 & 8-Aug-2002 & 12.34 & 0.43 \\
\hline 25-Jun-2002 & -15.62 & -1.40 & 9-Aug-2002 & 3.44 & -0.32 \\
\hline 26-Jun-2002 & -11.37 & -0.82 & 12-Aug-2002 & -32.19 & -1.86 \\
\hline 27-Jun-2002 & 14.92 & 1.49 & 13-Aug-2002 & $-77.55^{* *}$ & $-1.12 *$ \\
\hline 28-Jun-2002 & 12.78 & -0.40 & 14-Aug-2002 & 11.00 & 0.17 \\
\hline 1-Jul-2002 & -22.90 & $-0.98^{*}$ & 15-Aug-2002 & -46.56 & -1.29 \\
\hline 2-Jul-2002 & 2.31 & -1.16 & 16-Aug-2002 & -1.67 & -0.27 \\
\hline 3-Jul-2002 & -16.21 & $-1.46^{* *}$ & 19-Aug-2002 & $-33.12 *$ & $-0.90^{*}$ \\
\hline 5-Jul-2002 & $-29.71^{*}$ & $-2.03 * *$ & 20-Aug-2002 & $-5.97 * *$ & $-2.10 * *$ \\
\hline 8-Jul-2002 & -17.12 & -0.42 & 21-Aug-2002 & 1.38 & -0.70 \\
\hline 9-Jul-2002 & -9.31 & -0.84 & 22-Aug-2002 & -16.63 & 0.11 \\
\hline 10-Jul-2002 & -0.07 & 0.23 & 23-Aug-2002 & -55.27 & -0.41 \\
\hline 11-Jul-2002 & $7.61 * *$ & -1.17 & 26-Aug-2002 & -32.54 & 1.07 \\
\hline 12-Jul-2002 & $-5.75^{*}$ & $-1.88 * *$ & 27-Aug-2002 & $-108.59^{*}$ & -0.38 \\
\hline 15-Jul-2002 & -19.99 & $-1.61^{*}$ & 28-Aug-2002 & -0.95 & -0.19 \\
\hline 16-Jul-2002 & -2.11 & -0.83 & 29-Aug-2002 & -52.54 & $-1.44 *$ \\
\hline 17-Jul-2002 & -56.58 & -1.07 & 30-Aug-2002 & 0.07 & 0.01 \\
\hline
\end{tabular}

This table shows the differences in differences between the share-weighted relative effective spreads (in bps) between the "TRACE-eligible" and matched stocks from June 1, 2002 to August 30, 2002. The TRACE system was launched on July 1, 2002. We first calculate the daily differences in the effective spread between each "TRACE-eligible" stock and its matched stock. Then we compute the average of these daily differences over the base period from March 1, 2002 to May 31, 2002 and subtract it from the difference for each pair on each event day. The cross-sectional mean and median of these "differences in difference" are reported in the table. The alternative hypothesis of the t-test (Wilcoxon test) is that the mean (median) difference in effective spread between the "TRACE-eligible" stocks and the matched control stocks on each event day is smaller than that in the base period. The t-test is conducted using the standardized cross-sectional test proposed by Boehmer et al (1991). The difference in median is tested using the Wilcoxon Signed Rank test.

*The difference is statistically significant at $5 \%$ level. **The difference is statistically significant at $1 \%$ level. 
Table 3. Multivariate Regression of Differences in the Share-Weighted Relative Effective Spreads of "TRACE-eligible" Stocks and Matched Control Stocks around TRACE Initiation

Panel A: Full Sample and Subsets by Bond Rating

\begin{tabular}{|c|c|c|c|c|}
\hline & \multirow{2}{*}{ Full Sample } & \multicolumn{3}{|c|}{ Average Bond Rating } \\
\hline & & High & Med & Low \\
\hline \multirow[t]{2}{*}{ Intercept } & $-26.85 * *$ & $-49.07 * *$ & $-8.63 * *$ & $-20.80 * *$ \\
\hline & $(-12.11)$ & $(-8.27)$ & $(-3.71)$ & $(-7.27)$ \\
\hline \multirow[t]{2}{*}{ Difference in Price Inverse } & $191.83 * *$ & $189.43 * *$ & $200.25 * *$ & $183.66^{* *}$ \\
\hline & $(10.81)$ & (9.11) & (4.07) & (4.67) \\
\hline \multirow[t]{2}{*}{ (Difference in Trade Size) $* 10^{3}$} & $6.35^{* *}$ & $10.62 * *$ & 2.91 & $6.18^{*}$ \\
\hline & $(3.57)$ & $(3.32)$ & $(1.24)$ & $(2.18)$ \\
\hline \multirow[t]{2}{*}{ (Difference in Number of Trade)* $10^{3}$} & $-1.99 * *$ & $-2.57 * *$ & $-1.52 * *$ & -0.55 \\
\hline & $(-6.95)$ & $(-5.83)$ & $(-3.56)$ & $(-0.87)$ \\
\hline \multirow[t]{2}{*}{ Difference in Price Volatility } & $1170.16^{* *}$ & $2209.11 * *$ & $980.33^{* *}$ & $547.03 * *$ \\
\hline & $(10.36)$ & $(8.51)$ & (4.42) & $(5.01)$ \\
\hline \multirow[t]{2}{*}{ TRACE } & $-12.84 * *$ & $-28.98 * *$ & $-3.85 * *$ & $-10.89^{* *}$ \\
\hline & $(-10.56)$ & $(-8.61)$ & $(-3.35)$ & $(-5.38)$ \\
\hline Adjusted R-square & $69 \%$ & $71 \%$ & $70 \%$ & $61 \%$ \\
\hline
\end{tabular}

Panel B: Subsets by Probability of Informed Trading

\begin{tabular}{lrrr}
\hline & High & \multicolumn{2}{c}{ Low } \\
\hline Intercept & $-10.86^{* *}$ & $-19.21^{* *}$ & $-52.89^{* *}$ \\
& $(-7.89)$ & $(-5.11)$ & $(-8.35)$ \\
Difference in Price Inverse & $503.74^{* *}$ & $191.66^{* *}$ & $190.78^{* *}$ \\
& $(11.70)$ & $(4.04)$ & $(8.08)$ \\
(Difference in Trade Size)*10 $0^{3}$ & 4.59 & $8.01^{*}$ & 6.31 \\
& $(1.52)$ & $(2.50)$ & $(1.46)$ \\
(Difference in Number of Trade)*10 $10^{3}$ & $-6.59^{* *}$ & $-3.64^{*}$ & $-7.03^{* *}$ \\
Difference in Price Volatility & $(-3.62)$ & $(-2.16)$ & $(-6.20)$ \\
& $430.83^{* *}$ & $(3.92)$ & $1855.45^{* *}$ \\
TRACE & $(6.57)$ & $-7.37 * *$ & $(7.76)$ \\
& $-5.72^{* *}$ & $(-3.34)$ & $-24.08^{* *}$ \\
Adjusted R-square & $(-3.59)$ & $50 \%$ & $(-7.39)$ \\
\hline
\end{tabular}

Panel C: Subsets by Bond Trading Activity

\begin{tabular}{lrrr}
\hline & High & \multicolumn{2}{c}{ Low } \\
\hline Intercept & $-28.82^{* *}$ & $-37.12^{* *}$ & $-16.16^{* *}$ \\
& $(-6.60)$ & $(-8.13)$ & $(-6.46)$ \\
Difference in Price Inverse & $190.45^{* *}$ & $191.00^{* *}$ & $200.62^{* *}$ \\
& $(6.89)$ & $(6.93)$ & $(4.87)$ \\
(Difference in Trade Size) ${ }^{*} 10^{3}$ & 4.56 & $6.66^{*}$ & $8.56^{* *}$ \\
& $(1.72)$ & $(2.20)$ & $(3.08)$ \\
(Difference in Number of Trade) $)^{*} 10^{3}$ & $-1.31 * *$ & $-8.51^{* *}$ & $\left(-12.54^{* *}\right.$ \\
Difference in Price Volatility & $(-4.10)$ & $1360.18^{* *}$ & $(-4.54)$ \\
& $1329.37 * *$ & $(6.29)$ & $878.56^{* *}$ \\
TRACE & $(6.81)$ & $-13.99 * *$ & $(4.97)$ \\
& $-10.61 * *$ & $(-5.20)$ & $-14.40^{* *}$ \\
Adjusted R-square & $(-5.23)$ & $68 \%$ & $(-7.62)$ \\
\hline
\end{tabular}

This table reports the results of time-series cross-sectional regressions of the fixed-effect model specified in equation (6). The t-statistics (in parentheses) are calculated using the Huber-White sandwich estimator.

*The difference is statistically significant at $5 \%$ level. **The difference is statistically significant at $1 \%$ level. 
Table 4. Multivariate Regression of Differences in the Realized Spreads, Adverse Selections and Quoted Spreads of "TRACE-eligible" Stocks and Matched Control Stocks around TRACE Initiation

\begin{tabular}{|c|c|c|c|}
\hline & Realized Spread & Adverse Selection & Quoted Spread \\
\hline \multirow[t]{2}{*}{ Intercept } & $-17.34^{* *}$ & $-9.51^{* *}$ & $-43.05 * *$ \\
\hline & $(-7.94)$ & $(-5.41)$ & $(-14.68)$ \\
\hline \multirow[t]{2}{*}{ Difference in Price Inverse } & $136.13^{* *}$ & $55.70 * *$ & $180.98 * *$ \\
\hline & $(7.90)$ & (3.34) & (8.39) \\
\hline \multirow[t]{2}{*}{ (Difference in Trade Size) $* 10^{3}$} & 2.32 & $4.02 * *$ & -1.42 \\
\hline & $(1.13)$ & $(3.30)$ & $(-0.90)$ \\
\hline \multirow[t]{2}{*}{ (Difference in Number of Trade)*10 } & $0.51 *$ & $-2.50 * *$ & $-2.37 * *$ \\
\hline & $(2.48)$ & $(-9.26)$ & $(-6.31)$ \\
\hline \multirow[t]{2}{*}{ Difference in Price Volatility } & -46.67 & $1216.84 * *$ & $1006.93 * *$ \\
\hline & $(-0.53)$ & (11.59) & (6.19) \\
\hline \multirow[t]{2}{*}{ TRACE } & $-6.70^{* *}$ & $-6.14 * *$ & -1.69 \\
\hline & $(-6.01)$ & $(-6.29)$ & $(-1.51)$ \\
\hline Adjusted R-square & $48 \%$ & $36 \%$ & $71 \%$ \\
\hline
\end{tabular}

This table reports the results of time-series cross-sectional regressions of the fixed-effect model specified in equation (6). The t-statistics (in parentheses) are calculated using the Huber-White sandwich estimator.

*The difference is statistically significant at $5 \%$ level. **The difference is statistically significant at $1 \%$ level. 